Các rốiloan chủ yếu ở mức đô nhe và vừa. Rối loạn chức năng tình dục nữ và rối loạn cương dương có liên quan đến tuổi bệnh nhân suy tim.Do vậy, cần có các biện pháp cần được can thiêp sớm và kip thời để cải thiện chất lượng cuộc sống của bệnhn nhân, đặc biệt giúp cải thiện rối loạn tình dục ở bệnh nhân suy tim chức năng tâm thu thất trái giảm.

\section{TÀI LIÊU THAM KHẢO}

1. Savarese, G. and L.H. Lund, Global Public Health Burden of Heart Failure. Card Fail Rev, 2017. 3(1): p. 7-11.

2. Rosman, L., et al., Sexual health concerns in patients with cardiovascular disease. Circulation, 2014. 129(5): p. e313-6.

3. Levine, G.N., et al., Sexual activity and cardiovascular disease: a scientific statement from the American Heart Association. Circulation, 2012. 125(8): p. 1058-72.

4. Schwarz, E.R., et al., The prevalence and clinical relevance of sexual dysfunction in women and men with chronic heart failure. Int J Impot Res, 2008. 20(1): p. 85-91.
5. Van Vo, T., H.D. Hoang, and N.P. Thanh Nguyen, Prevalence and Associated Factors of Erectile Dysfunction among Married Men in Vietnam. Front Public Health, 2017. 5: p. 94.

6. Ponikowski, P., et al., 2016 ESC Guidelines for the diagnosis and treatment of acute and chronic heart failure: The Task Force for the diagnosis and treatment of acute and chronic heart failure of the European Society of Cardiology (ESC)Developed with the special contribution of the Heart Failure Association (HFA) of the ESC. Eur Heart J, 2016. 37(27): p. 2129-2200.

7. Dickstein, K., et al., ESC guidelines for the diagnosis and treatment of acute and chronic heart failure 2008: the Task Force for the diagnosis and treatment of acute and chronic heart failure 2008 of the European Society of Cardiology. Developed in collaboration with the Heart Failure Association of the ESC (HFA) and endorsed by the European Society of Intensive Care Medicine (ESICM). Eur J Heart Fail, 2008. 10(10): p. 933-89.

8. Sand, M., et al., The female sexual function index (FSFI): a potential "gold standard" measure for assessing therapeutically-induced change in female sexual function. Fertility and Sterility, 2009. 92(3): p. S129.

\title{
MỐI LIÊN QUAN GIỮA THỰC TRANG KÉM KHOÁNG HOÁ MEN RĂNG (MIH) VÀ CHẤN THƯƠ'NG RĂNG SỮA, RĂNG SỮA MẤT SỚM Ở HỌC SINH 12-15 TUỔITẠI MộT SỐ TİNH THÀNH Ở VIỆT NAM
}

\section{TÓM TẮT}

Một bệnh lý đang được ngành Nha khoa trên thế giới quan tâm đến nhiều đó là kém khoáng hóa men răng hàm lớn - răng cửa (MIH). Bệnh không phát hiện và điều trị kịp thời có thể dần đến những hậu quả nghiêm trọng và gây mất răng. Nghiên cứu của chúng tôi được thực hiện trên 5294 hoc sinh ở tai mốt số tỉnh cưa Việt Nam như Bình Định, Thanh Hoá và Hải Phòng nhằm mục đích xác đinh tŷ lệ mắc bệnh ở các địa phương và một số mới liên quan để có kế hoạch điều trị và dự phòng cho phù hợp. Kết quả: tỷ lệ MIH chung của nhóm học sinh là 20,1\%, trong đó $\mathrm{MIH}$ nhẹchiếm 15,2\% tổng số đối tượng nghiên cứu và tỷ lệ MIH nặng là 4,9\%.Tỷ lệ nhiễm MIH ở răng hàm lớn và răng cửa lần lượt là $10,6 \%$ và $11,4 \%$. Các học sinh có tiền sử chấn thương răng sữa, răng sữa mất sớm có nguy cơ mắc MIH cao hơnlần lượt 1,12 lần và 1,26 lần. Kết luận: tỷ lệ mắc MIH là cao, có sự khác biệt về tỷ lệ mắc bệnh giữa các lứa tuổi và vị trí răng.

Tư khóa: Kém khoáng hóa men răng, MIH, học sinh.

*Trường Đại học Y Hà Nội

Chịu trách nhiệm chính: Võ Trương Như Ngọc

Email: votruongnhungoc@gmail.com

Ngày nhận bài: 9/3/2021

Ngày phản biện khoa học: 5/4/2021

Ngày duyệt bài: 2/5/2021

\section{Võ Trương Như Ngọc*, Hoàng Bảo Duy*}

\section{SUMMARY}

RELATION BETWEEN THE MOLAR-INCISOR HYPOMINERALIZATION (MIH) AND PRIMARY TEETH TRAUMA, EARLY

PRIMARY TEETH LOSS IN 12-15 YEAR-OLD PUPILS IN SOME PROVINCES, VIETNAM

Recent researchs indicates that molar-incisor hypomineralization (MIH) is more and more popular in dental condition worldwide. It can lead to serious consequences and cause tooth loss if not detected and treated in time. There are 5294 pupils in several provinces of Vietnam such as Binh Dinh, Thanh Hoa and Hai Phong participated in our research. This study aims to determine the prevalence of the disease in the locality and relation between the MIH and primary teeth traumatisme, early primary tooth loss to build suitable prevention and treatment plans. Results: the rate of general MIH of the pupils was $20.1 \%$, mild MIH accounted for $15.2 \%$ of the study subjects and the rate of severe MIH was $4.9 \%$. The prevalence of $\mathrm{MIH}$ in the molars and incisors was $10.6 \%$ and $11.4 \%$, respectively. Pupils with a history of primary teeth trauma and primary teeth loss had the risk of $\mathrm{MIH}$ 1.12 times and 1.26 times higher, respectively. Conclusion: The incidence of $\mathrm{MIH}$ is high, there is a difference in the rate of disease between ages and tooth position. 
Keywords: Molar-Incicor Hypomineralization, $\mathrm{MIH}$, pupils.

\section{I. ĐĂT VẤN ĐỀ}

MIH là một tình trạngkém khoáng hóa men răng hay gặp, tỷ lệ mặc bệnh hiện nay có thể thay đổi tuỳ theo nghiên cứu. Tình trạng này có thể liên quan đến các biến chứng nha khoa, có thể ảnh hưởng đến chất lượng cuộc sống của bệnh nhân cũng như tạo ra những thách thức cho các bác sĩ điều trị. Răng bị MIH dễ bị sâu răng và võ men răng khi ăn nhai. Chẩn đoán sớm có thể giúp kiểm soát các bệnh lý có thể đi theo, hậu quả của MIH.

Các nghiên cứu dich tễ hoc từ các khu vực khác nhau trên thế giới cho thấy sự khác biệt lớn về tỷ lệ mắc $M I H$, có thể dao động từ 2,8 $40,2 \%$, tuy nhiên, sự khác biệt này có thể là do thiếu các công cự tiểu chuẩn để ghi lại MIH dẫn đến đánh giá thấp tỷ lệ hiện mắc. Để khắc phục, Ghanim đã giới thiệu một hệ thống tính điểm chuẩn dựa trên các tiêu chí đánh giá của Viện hàn lâm nhi khoa châu Âu (EAPD) ${ }^{1}$. Một hướng dẫn cũng đã được xuất bản gần đây để tạo điều kiện và tiêu chuẩn hóa việc sử dụng nó trong các nghiên cứu dịch tễ học trong tương lai. Elfrink đề xuất rằng ít nhất 300 đối tượng nên tham gia vào các nghiên cứu như vậy. Hiện tại, người ta ước tính rằng tình trạng này ảnh hưởng đến $1 / 6$ trẻ em trên toàn thế giới.

\section{II. ĐỐI TƯỢNG VÀ PHƯƠNG PHÁP NGHIÊN CỨU}

Nghiên cứu được thực hiện ở 3 tỉnh và thành phố là: Bình Định, Thanh Hoá và Hải Phòng

\section{1. Đối tượng nghiên cứu}

Tiêu chuẩn lưa chon: Học sinh từ 12-15 tuổi đang sinh sống và học tập tại tỉnh Bình Định, Thanh Hoá và Hải Phòng; Học sinh tự nguyện tham gia nghiên cứu; Không có vấn đề về tâm thần, dị tật bẩm sinh.

Tiêu chuấn loại trừ: Học sinh không có khả năng hợp tác tham gia nghiên cứu, đối tượng đang trong quá trình chỉnh nha.

\subsection{Phương pháp nghiên cứu}

- Nghiên cứu được thiết kế theo phương pháp mô tả cắt ngang để xác định tỷ lệ mắc bệnh trong quân thể. Cỡ mẫu nghiên cứu được tính theo công thức cho ước lượng một tỷ lệ.

$$
n=z_{\left(1-\frac{a}{2}\right)}^{2} \frac{p q}{d^{2}}
$$

Trong đó: n: là cõ̃ mẫu nghiên cứu, $\mathrm{Z}_{(1-a / 2) \text { : }}$ hệ số tin cậy $=1,96, \mathrm{p}$ : tỷ lệ kém khoáng hóa răng hàm - răng cửa, q: 1-p, d: độ sai lệchmong muốn (2\%).
Tỷ lệ kém khoáng hóa men răng hàm lớn răng cửa ước tính là $9,46 \%$ theo nghiên cứu củaShubha Arehalli Bhaskarvà cộng sự năm $2014^{2}$. Thay vào công thức trên ta có cõ mẫu tối thiểu cần là: 823 đối tượng nghiên cứu cho mỗi tỉnh, thành phố.

- Tiêu chuẩn chẩn đoán trong nghiên cứu. Trong nghiên cứu này, chúng tôi sử dụng tiêu chuẩn của Liên đoàn nha khoa trẻ em Châu âu (EAPD) đưa ra vào năm 2010. Theo tiêu chuân này, MIHphân loại như sau:

+ MIH nhe: Các mảng màu đưc xuất hiện trên răng hàm hoặc răng cửa mà không có sự phá hủy men sau mọc răng. Độ nhạy cảm răng bình thường và không có vấn đề về thẩm mỹ.

+ MIH trung bình: các đốm đục có ranh giới hiện diện trên răng hàm và răng cửa, hiện tượng vỡ men răng sau khi mọc giới hạn ở một hoặc hai bề mặt mà mặt nhai còn tồn tại, có thể cần có các phục hình không đặc hiệu và độ nhạy cảm răng bình thường.

+ MIH nặng: Có hiện tượng phá hủy men sau khi mọc răng, phá hủy thân răng, sâu răng liên quan đến răng bị ảnh hưởng, có tiền sử nhạy cảm răng và có các vấn đề về thẩm mỹ.

MIH được ghi nhận trên mặt nhai, mặt ngoài, mặt trong và mặt bền của các răng hàm lớn và các răng cửa vĩnh viễn. Các tổn thương được ghi nhận khi có kích thước lớn hơn $1 \mathrm{~mm}$ theo $\mathrm{EAPD}^{3}$. MIH được chẩn đoán khi một răng hàm lớn hoặc răng cửa vĩnh viện bị ảnh hưởng bởi kém khoáng hóa

\section{Các bước tiến hành nghiên cứu}

- Tập huấn nhóm nghiên cứu theo chỉ số Kappa trước khi tiến hành thu thập số liệu theo tiêu chuẩn chẩn đoán như đã nêu trên. Các hình ảnh mẫu về bênh lý MIH cũng như các bênh lý cân chẩn đoán phân biệt như: nhiễm Fluor, thiểu sản men, sinh men bất toàn, tổn thương sâu răng giai đoạn sớm... cũng được sử dụng để tập huấn. Các nghiên cứu viên được tập huấn cách khám, tiêu chuẩn chẩn đoán cũng như cách ghi phiếu khám và các bộ câu hỏi kèm theo.

- Liên lạc với địa phương, chọn địa điểm khám và lập danh sách đối tượng nghiên cứu.

- Nhà trường hỗ trợ gửi thông báo cho các gia đình để xin ý kiến đồng ý của gia đình.

- Tiến hành thu thập dữ liệu

- Vào số liệu, phân tích số liệu và viết báo cáo

Quy trình khám lâmm sàng: Khám trên các răng hàm lớn vĩnh viễn và các răng cửa vĩnh viễn. Khám lần lượt từ các cung răng 1,2,3,4 tránh bỏ sót. Khám lâm sàng được thực hiện dưới ánh sáng tự nhiên, khi trời tối có sử dụng 
đèn led đeo trán để hỗ trợ. Răng không được làm khô trước nhưng khi cần thiết thì làm sạch và làm khô bề mặt răng bằng gạc và quả bóng làm khô hoặc bình khí nén. Gương và cây thăm dò nha chu được sử dung để thăm khám.

2.3. Đạo đức nghiên cứu. Nghiên cứu được thực hiện tuân thủ theo các qui định của đạo đức nghiển cứu y sinh học. Học sinh được tư vẩn và thông báo cho gia đình tình trạng sức khoẻ răng miệng. Mọi thông tin thu thập đều được bảo mật và nhằm mục đích nghiên cứu.

\section{KẾT QUẢ NGHIÊN CỨU}

3.1. Đặc điểm của nhóm đối tượng nghiên cứu

Bảng 3.1. Đặc điểm chung của đôi tượng nghiên cứu

\begin{tabular}{|c|c|c|}
\hline Đắc điếm & Số lượng (n) & Tỷ lệ (\%) \\
\hline Giới: Nam & 2570 & 48,55 \\
\hline Nữ & 2724 & 51,45 \\
\hline Tuối: 12 & 1386 & 26,18 \\
\hline 13 & 1371 & 25,90 \\
\hline 14 & 1314 & 24,82 \\
\hline 15 & 1223 & 23,10 \\
\hline
\end{tabular}

Nhận xét: Có tống cộng 5294 học sinh tham gia vào nghiên cứu, trong đó tỷ lệ nam và nữ tương đương nhau với 2570 nam chiếm 48,55\% và 2724 nữ chiếm $51,45 \%$. Tất cả học sinh đều từ 12 đến 15 tuổi, trong đó số học sinh 12 tuổi là lớn nhất 1386 em $(26,18 \%)$ và số học sinh 15 tuổi là nhỏ nhất 1223 em (23,10\%).

3.2. Đặc điểm kém khoáng hóa men răng hàm lớn - răng cửa và sâu răng ở nhóm nghiên cứu. Có 1064 người mắc MIH chiếm $20,1 \%$ tổng số đối tượng nghiên cứu, số người không mắc là 4230 em $(79,9 \%)$, nhiều gấp 4 lần số người có MIH. Trong số mắc bệnh có 530 nam, 534 nữ, tính chung theo giới, tỳ lệ nam mắc bệnh là $20,6 \%$, nữ là $19,6 \%$.

Bảng 3.2. Tý lệ kém khoáng hóa men răng hàm lớn - răng cửa theo loại tôn thương

\begin{tabular}{|c|c|c|}
\hline Loaai tổn thương & Số người & $\mathbf{\%}$ \\
\hline Tống số người & 5294 & 100 \\
\hline MIH & 1064 & 20,1 \\
\hline MIH nhẹ & 805 & 15,2 \\
\hline MIH nặng & 259 & 4,9 \\
\hline
\end{tabular}

Nhận xét: Có 1064 người mắc MIH, trong đó số người có MIH nhe là 805 , chiếm $15,2 \%$ tổng số đối tượng tham gia nghiên cứu, số người có MIH nặng là 259, chiếm 4,9\% tổng số đối tượng nghiên cứu.

Bảng 3.3. Phân bố tổn thương kém khoáng hóa men răng hàm lớn - răng cửa theo vị trí răng

\begin{tabular}{|c|c|c|c|c|c|}
\hline & $\begin{array}{c}\text { Số } \\
\text { người }\end{array}$ & $\%$ & $\begin{array}{c}\text { Số } \\
\text { người }\end{array}$ & \% & value \\
\hline MIH & 563 & 10,6 & 606 & 11,4 & \multirow{2}{*}{0,000} \\
\hline $\begin{array}{c}\text { Không } \\
\text { MIH }\end{array}$ & 4731 & 89,4 & 4688 & 88,6 & \\
\hline Tống & 5294 & 100 & 5294 & 100 & \\
\hline
\end{tabular}

Chi-square test

Nhận xét: Số người có răng hàm bị mắc MIH là 563, chiếm 10,6\% tổng số học sinh nghiên cứu, số người không có răng hàm bị mắc MIH là 4731, chiếm 89,4\%. Tỷ lệ người mắc MIH ở răng cửa cao hơn răng hàm với 606 học sinh chiếm $11,4 \%$, số người không có răng cửa bi mắc MIH là 4688, chiếm $87,0 \%$. Sự khác biệt có ý nghĩa thống kê với $p<0,001$.

Bảng 3.4. Phân bố mức độ tổn thương kém khoáng hóa men răng hàm lớn - răng cửa theo vị trí răng

\begin{tabular}{|c|c|c|c|c|}
\hline \multirow{2}{*}{} & \multicolumn{2}{|c|}{ Răng hàm } & \multicolumn{2}{c|}{ Răng cửa } \\
\cline { 2 - 5 } & $\begin{array}{c}\text { Số } \\
\text { người }\end{array}$ & $\%$ & $\begin{array}{c}\text { Số } \\
\text { người }\end{array}$ & \% \\
\hline MIH nhẹ & 200 & 62,5 & 209 & 76,0 \\
\hline MIH nặng & 120 & 37,5 & 66 & 24,0 \\
\hline p $^{2}$ & \multicolumn{2}{|c|}{0,000} & \multicolumn{2}{c|}{0,007} \\
\hline
\end{tabular}

Chi-square test

Nhận xét: Có 200 người có MIH mức độ nhe ở răng hàm (62,5\%), 120 người có MIH nặng ở răng hàm chiếm $37,5 \%$. Sự khác biệt có ý nghĩa thống kê với $p<0,001$. Có 209 người có MIH mức độ nhe ở răng cửa $(76,0 \%), 66$ người có MIH mức độ nặng ở răng cửa chiếm $24,0 \%$. Sự khác biệt có ý nghĩa thông kê với $p<0,01$.

3.3. Mối liên quan giữa chấn thương răng sữa và răng sữa mất sớm với khém khoáng hoá men răng

Bảng 3.5. Mối liên quan giữa chấn thương răng sữa với tỷ lệ kém khoáng hóa men răng hàm lớn - răng cửa (MIH)

\begin{tabular}{|c|c|c|c|}
\hline & $\begin{array}{c}\text { Chấn } \\
\text { thương } \\
\text { Số người } \\
(\%)\end{array}$ & \begin{tabular}{|c|}
$\begin{array}{c}\text { Không chấn } \\
\text { thương }\end{array}$ \\
$\begin{array}{c}\text { Số người } \\
(\%)\end{array}$ \\
\end{tabular} & $\begin{array}{c}\text { OR } \\
(95 \% \\
\text { CI })\end{array}$ \\
\hline MIH & $185(21,6)$ & $879(19,8)$ & \multirow{3}{*}{$\begin{array}{r}1,12 \\
(0,94- \\
1,34) \\
\end{array}$} \\
\hline Không MIH & $670(78,4)$ & $3560(80,2)$ & \\
\hline Tống & $(100)$ & $(100)$ & \\
\hline
\end{tabular}

Phân tích hồi quy logistic đơn biến

Nhận xét: Có 185 người có chấn thương răng sữa có $M I H$, chiếm $21,6 \%$ số người có chấn thương răng sữa. Tỷ lệ người không chấn thương răng sữa có mắc MIH thấp hơn người có chấn thương (879 người chiếm 19,8\%). Trẻ có chấn thương răng sữacó nguy cơ mắc MIH cao gấp 1,12 lần trẻ không có chấn thương, sự khác 
biệt không có ý nghĩa thống kê với p > 0,05.

Bảng 3.6. Mối liên quan giữa mất răng sữa sớm do sâu răng và kém khoáng hóa men răng hàm lớn - răng cửa (MIH)

\begin{tabular}{|c|c|c|c|}
\hline & $\begin{array}{c}\text { Mất răng } \\
\text { sữa } \\
\text { Số người } \\
(\%)\end{array}$ & \begin{tabular}{|c|}
$\begin{array}{c}\text { Không mất } \\
\text { răng sữa }\end{array}$ \\
$\begin{array}{c}\text { Số người } \\
(\%)\end{array}$ \\
\end{tabular} & $\begin{array}{c}\text { OR } \\
(95 \% \\
\text { CI })\end{array}$ \\
\hline $\mathrm{MIH}$ & $269(23,1)$ & $795(19,3)$ & 1,26 \\
\hline Không MIH & $897(76,9)$ & $3333(80,7)$ & $(1,07-$ \\
\hline Tống & $1166(100)$ & $4128(100)$ & $1,47)$ \\
\hline
\end{tabular}

Phân tích hồi quy logistic đơn biến

Nhận xét: Có 269 người có mất răng sữa sớm do sâu có MIH, chiếm $23,1 \%$ số người có mất răng sữa sớm do sâu. Tỷ lệ người không mất răng sữa sớm do sâu có mắc MIH thấp hơn người có mất răng (795 người chiếm 19,3\%). Trẻ có mất răng sữa sớm do sâu có nguy cơ mắc MIH cao gấp 1,26 lần trẻ không mất răng, sự khác biệt có ý nghĩa thống kê với $p<0,01$.

\section{BÀN LUÂ̂N}

Nghiên cứu được thực hiện trên 5294 học sinh 12-15 tuổi, tỷ lệ nam nữ gần như nhau. Tỷ lệ mắc MIH trung bình cho cả hai giới là $20,1 \%$, trong đó tỷ lệ mắc thể nhẹ 15,2\%, nặng là 4,9\% nếu tính trung bình trên 5249 học sinh. Tỷ lệ này là cao và cũng tương tự với nhiều nghiên cứu khác ở các nước khác trên thế giới. Cristiane Maria da Costa-silva và cộng sựnghiên cứu trên 918 trẻ độ tuổi 6-12 tuổi ở Minas Gerais, Brazilcó tỷ lệ mắc là $19,8 \%{ }^{4}$. Tỷ lệ mắc bệnh cũng thay đổi rất nhiều theo từng nghiên cứu, phụ thuộc vào địa điểm nghiên cứu và độ tuổi nghiên cứu. So sánh với nghiên cứu của Shubha Arehalli Bhaskarvà cộng sự năm 2014 với sự tham gia của 1173 trẻ em ở độ tuổi từ 8-13 tại Udaipur có kết quả là MIH nhe chiếm 48,5\% và MIH nặng chiếm $51,5 \%$ cho thấy tỷ lệ phân bố đồng đều hơn?

Điểm đặc biệt trong nghiên cứu này là không có ca nào thể trung bình. Có thể nghiên cứu của chúng tôi ở trẻ 12-15 tuổi, một số răng thể trung bình trong quá trình diễn biển bệnh, ăn nhai bị tổn thưuong võ rộng nên khi đánh giá chúng tôi đã đánh giá là độ nặng. Ngoài ra, trên nền MIH rất dễ bị sâu răng, nên nếu có sâu răng kèm theo trên nền MIH thì việc chẩn đoán sẽ phức tạp hơn nhiều và dễ nhầm lẫn giữa sâu răng và Sâu răng trên nền MIH. Do vậy, để nghiên cứu MIH thì tốt hỡn nên nghiên cứu ở các lứa tuổi nhỏ hơn để dễ chẩn đoán xác định và phân biệt với các bệnh lý khác kèm theo. Lứa tuổi tốt nhất là 7-8 tuổi.
Trong mẫu nghiên cứu có 185 người có chấn thương răng sữacó $\mathrm{MIH}$, chiếm $21,6 \%$ số người có tiền sử chấn thương răng sữa. Nhóm không có tiền sử chấn thương răng sữacó tỷ lệ mắc MIH thấp hơn người có chấn thương (chiếm 19,8\%). Trẻ có chấn thương răng sữa có nguy cơ mắc MIH cao gấp 1,12 lần trẻ không có chấn thương khi phân tích hồi qui đơn biến, tuy nhiên sự khác biệt không có ý nghĩa thống kê với $p>0,05$.

Trong mẫu nghiên cứu có 269 người có mất răng sữa sớm do sâu có $M I H$, chiếm $23,1 \%$ số người có mất răng sữa sớm do sâu. Nhóm không mất răng sữa sớm do sâu có mắc MIH thấp hơn người có mất răng (chiếm 19,3\%). Trẻ có mất răng sữa sớm do sâu có nguy cơ mắc MIH cao gấp 1,26 lần trẻ không mất răng, sự khác biệt có ý nghĩa thống kê với $p<0,01$. Như vậy, cho thấy, những trường hợp vì lý do nhiễm trùng (hậu quả của sâu răng) phải nhổ răng, nguy cơ mắc MIH cao hơn nhiều so với trẻ không bị mất răng sớm, hay nói khác hơn là những trẻ được chăm sóc răng miệng tốt, bảo vệ được bộ rẳng sữa đến tuổi thay. Răng sữa có nhiều chức năng quan trọng như ăn nhai, phát âm, thẩm mỹ, giữ chỗ, kích thích sự phát triển của xương hàm, do vậy bảo vệ được bộ răng sữa tốt không chỉ giúp tránh mắc bệnh MIH cho các răng vĩnh viễn mà còn giúp cho trẻ đảm bảo các điều kiện phát triển một cách toàn diện hơn về thế chất cũng như tinh thần.

\section{KẾT LUÂ̂N}

Tỷ lệ mắc MIH ở các tỉnh Bình Định, Thanh Hoá và Hải Phòng là cao và cũng giống như nhiều nước phát triển trên thế giới. Trẻ em có tiền sử chấn thương không thây có nguy cơ mắc MIH cao hơn trẻ không có tiền sử chấn thương. Trẻ có tiền sử mất răng sữa sớm có nguy cơ mắc MIH 1,26 lần. Do vậy, cần tăng cường công tác chăm sóc răng miệng cho trẻ nhỏ và nên có các nghiên cứu sâu và rộng hơn để xác định các yếu tố nguy cơ khác để có kế hoạch dự phòng và điều trị phù hợp.

\section{LỜI CẢM ƠN}

Để hoàn thành được bài báo này, chúng tôi xin chân thành cảm ợn sâu sắc tới các học sinh và các trường học đã tham gia nghiên cứu. Đồng thời chúng tôi chân thành cảm ơn sự hỗ trợ của các đồng nghiệp, các bạn học viên đã tham gia nghiên cứu.

\section{TÀI LIẸU THAM KHẢO}

1. Ghanim A, Elfrink M, Weerheijm K, Mariño R, Manton D. A practical method for use in epidemiological studies on enamel 
hypomineralisation. Eur Arch Paediatr Dent. 2015;16(3):235-46.

2. Bhaskar SA, Hegde S. Molar-incisor hypomineralization: prevalence, severity and clinical characteristics in 8- to 13-year-old children of Udaipur, India. J Indian Soc Pedod Prev Dent. 2014;32(4):322-9.

3. Weerheijm K. The European Academy of
Paediatric Dentistry and Molar Incisor Hypomineralisation. Eur Arch Paediatr Dent. 2015;16(3):233-4.

4. da Costa-Silva CM, Jeremias F, de Souza JF, Cordeiro Rde C, Santos-Pinto L, Zuanon AC. Molar incisor hypomineralization: prevalence, severity and clinical consequences in Brazilian children. Int J Paediatr Dent. 2010;20(6):426-34.

\section{CÁC YẾU Tố TIÊN LƯợNG HIỆU QUẢ CỦA PHÁC Đồ PEMETREXED - CARBOPLATIN ĐIỀU TRI UNG THƯ PHỔI KHÔNG TẾ BÀO NHỎ SAU KHÁNG THUỐC ỨC CHẾ EGFR TYROSINE KINASE}

\section{TÓM TẮT}

Mục tiêu: Đánh giá các yếu tố tiên lượng hiệu quả của phác đồ Pemetrexed - Carboplatin điều tri ung thư phổi không tế bào nhỏ giai đoạn tiến xa có đột biến EGFR. Đối tượng và phương pháp: 46 bểnh nhân ung thư phổi không tế bào nhỏ giai đoạn tiến xa có đột biến EGFR, kháng thứ phát với TKİs, không có hoằc không biết đột biến T790M, điều trị hoá chất phác đồ Pemetrexed - Carboplatin. Nghiên cứu hồi cứu có theo dõi doc. Kết quả: PSO có mPFS 5 tháng, PS1 có mPFS 3,5 tháng. mPFS ở bệnh nhân di căn não: 3,3 tháng; không có di căn não: 5,6 tháng. mPFS cho giai đoạn IIIB là 7 tháng, giai đoạn IV là 3 tháng. Đáp ứng TKI trên 6 tháng với mPFS 7 tháng, đápứng dưới 6 tháng với mPFS 2,5 tháng. Kết luận: Di căn não, giai đoạn IV, thời gian đáp ứng với điều trị bước 1 TKI dưới 6 tháng là những yếu tố tiên lượngsốngthêmkhông bệnh tiến triển ngắn với điều trị Pemetrexed - Carboplatin.

Tư khoá: Ung thư phổi không tế bào nhỏ, kháng thứ phát với EGFR TKIs, hóa trị, sống thêm không tiến triển bệnh

\section{SUMMARY \\ PROGNOSIS FACTORS OF ADVANCED STAGE NON-SMALL LUNG CANCER AFTER EGFR TKIS ACCQUIRED RESISTANCE \\ Objective: To evaluate prognosis factors of advanced non-small cell lung cancer after accquired resistance to EGFR TKIs treated with Pemetrexed - Carboplatin regimen. Objects and methods: 46 patients with advanced non-small cell lung cancer with EGFR mutation, secondary resistance to TKIs, no or unknown T790M mutation, treatment withPemetrexed - Carboplatin. Retrospective studies with vertical follow-up. Results: PS0 has mPFS for 5 months, PS1}

\footnotetext{
${ }^{1}$ Bệnh viện Hữu Nghi Việt Xô

²Bệnh viện $K$ Trung ương

Chịu trách nhiệm chính: Nguyễn Thị Thái Hoà

Email: bshoabvk@gmail.com

Ngày nhận bài: 5/3/2021

Ngày phản biện khoa học: 1/4/2021

Ngày duyệt bài: 28/4/2021
}

\section{Mai Thanh Huyền ${ }^{1}$, Nguyễn Thị Thái Hoà ${ }^{2}$}

has mPFS for 3.5 months. mPFS in patients with brain metastasis: 3.3 months; no brain metastases: 5.6 months. mPFS for phase IIIB is 7 months, phase IV is 3 months. A TKI response over 6 months with an mPFS of 7 months, a response less than 6 months with an mPFS of 2.5 months. Conclusion: Brain metastasis, stage IV, response time to first line treatment TKI less than 6 months are prognostic factors with short progression - free survival with Pemetrexed - Carboplatin treated.

Keywords: Lung cancer, non-small cell, secondary resistance to EGFR TKIs, chemotherapy, progression - free survival

\section{I. ĐẶT VẤN ĐỀ}

Phác đồ hóa trị pemetrexed - platinum là một trong những phác đồ tiêu chuẩn để điêuu trị bước 1 ung thư phổi không tế bào nhỏ giai đoạn tiến xa với mô bệnh học không phải tế bào vảy. Theo tác gỉa Scagliotti và cộng sự (2009), sông thêm trung vị đạt 12,6 tháng; các tác dụng không mong muốn trên hệ tạo huyết giảm đáng kể so với phác đồ gemcitabin - cisplatin [1].

Đối với nhóm bệnh nhân kháng thuốc sau điều trị EGFR TKIs, nếu bệnh nhân không có hoặc không biết tình trạng đột biến kháng thuốc T790M, hóa trị là lựa chọn phổ biến. Tuy Cisplatin là lựa chọn đẩu tay cho các phác đồ bộ đôi trong điều trị UTP giai đoạn muộn, cho tỷ lệ đáp ứng cao hơn Carboplatin nhưng lại có nhiêu tác dụng phụ trên thận, hệ tạo huyết, nôn, buôn nôn nhiều hởn, trong khi Carboplatin cùng nhóm ít tác dụng phụ hơn, phù hợp với các bệnh nhân thể trạng yếu đặc biệt ở nhóm đối tượng điều trị bước 2 sau kháng thứ phát TKIs. Chính bởi vậy, nhiều thày thuốc lựa chọn phác đồ pemetrexed carboplatin cho nhóm bệnh nhân này.

Do đó, chúng tôi tiến hành đề tài này nhằm mục tiêu: Đánh giá các yếu tố ảnh hưởng thời gian sống thêm không tiến triển bệnh ung thư phổi không tế bào nhỏ điều trị phác đồ 